\title{
Lagar II, de Gabriela Mistral: historia de sus manuscritos y versiones del poema "Convite a la danza"
}

Recibido: marzo 22 de 2017 | Aceptado: enero 30 de 2018

DOI: 10.17230/co-herencia.15.29.11

\section{Yenny Ariz Castillo* \\ yariz@ucsc.cl}

Resumen La primera parte del presente artículo expone los resultados de una investigación sobre los manuscritos del poemario póstumo Lagar II (1991) de Gabriela Mistral. La segunda parte se hace cargo de la recepción del texto por parte de los académicos chilenos. Por último, la tercera parte se centra en el estudio del poema que abre Lagar II, "Convite a la danza”, y sus versiones, demostrando la utilización de estrofas desechadas de versiones preliminares del poema en ediciones póstumas, en las que estos fragmentos figuran como poemas inéditos. El análisis se realiza de acuerdo con los postulados de la "crítica genética", en especial, se utiliza el concepto "dossier de génesis".

\section{Palabras clave:}

Gabriela Mistral, Lagar II, Almácigo, Baila y sueña, manuscritos, crítica genética.

\section{Lagar II, by Gabriela Mistral: a history of the poetry collection's manuscripts and the various versions of the poem 'Convite a la danza'}

\begin{abstract}
The first section of this paper reports the results of a research study on the manuscripts included in the posthumous poetry collection Lagar II (1991) by Gabriela Mistral. The second section addresses the reception of the text by Chilean scholars. Finally, the third section focuses on the study of both the first poem of Lagar II collection -Convite a la danza'- and of its various versions, demonstrating the use of stanzas discarded from preliminary versions of the poem in posthumous editions, in which these fragments appear as unpublished works. The analysis follows the theoretical principles of the so-called 'genetic criticism', particularly, the concept of 'genetic dossier'.
\end{abstract}

\section{Keywords:}

Gabriela Mistral, Lagar II, Almácigo, Baila y sueña, manuscripts, genetic criticism
Este artículo es resultado del proyecto de investigación FONDECYT postdoctoral N. 3150189, titulado "La poesía póstuma de Gabriela Mistral: el yo poético ante el 'sueño maravilloso"' (20152016).

** Doctora en Literatura Latinoamericana. Académica de la Universidad Católica de la Santísima Concepción, Chile. ORCID ID: 0000-0003-0421-8907 
"[...] antes de morir deseo y debo recopilar un volumen de páginas escogidas, porque Dios sabe lo que se le ocurrirá publicar a los editores una vez que haya muerto".

(G. Mistral, en La divina Gabriela, Virgilio Figueroa, 1933)

Publicado en 1991 por la Dirección de Bibliotecas, Archivos y Museos de Chile (DIBAM), y reeditado en 1992 por la misma institución, Lagar II reúne cincuenta y ocho poemas, de los cuales seis poseen una versión alternativa, lo que nos da un total de sesenta y cuatro textos. ${ }^{1}$ Su edición es el resultado del trabajo de una comisión de especialistas integrada por Pedro Pablo Zegers y Mario Andrés Salazar de la DIBAM, los profesores de literatura Ana María Cuneo y Gastón von dem Bussche, y el representante de la Academia Chilena de la Lengua, Alfredo Matus, quienes dedicaron seis meses a leer y transcribir los manuscritos vinculados a la obra (P. P. Zegers, entrevista personal, enero 23, 2015).

En el presente artículo se comenta la historia de la edición de Lagar II y su recepción, para luego examinar las versiones del poema "Convite a la danza", a fin de cotejar las ediciones póstumas de la poesía mistraliana con los originales. ${ }^{2}$ El análisis de estos documentos se hace a partir de los postulados de la crítica genética, enfoque teórico de origen francés que estudia en "todas las fases documentadas, existentes, de la creación literaria, los mecanismos a través de los cuales un autor forma su obra" (Pastor, 2008, p. 15). En específico, examinaremos el dossier génétique (dossier de génesis) de Lagar II, término que se define, según Almuth Grésillon, como: "un ensemble constitué par les document écrits que l'on peut attribuer dans l'aprèscoup à un projet d'écriture déterminé dont il importe peu qu'il ait abouti ou non à un texte publié" (1994, p. 108). De este modo, revisaremos el dossier de génesis de Lagar II involucrando manuscritos, epistolarios de los editores, declaraciones a la prensa y reflexiones en revistas especializadas, para, finalmente, enfocarnos en el dossier específico de "Convite a la danza" y sus ediciones. ${ }^{3}$

1 En la Antología Mayor (1992) se publicó una copia de Lagar II en el primer volumen, dedicado a la poesía.

2 Esta investigación fue posible gracias al trabajo de catalogación y digitalización de la Biblioteca Nacional de Chile, que se encuentra a disposición del público en el sitio web de la Institución.

3 La crítica genética nace con el objetivo de aportar a una mejor comprensión de las obras 


\section{Historia de Lagar II}

Aunque median veinticuatro años entre las ediciones de Poema de Chile (1967) y Lagar II, las tentativas de publicación de esta última obra por parte de la albacea de Mistral, Doris Dana, comenzaron en conjunto con las gestiones para editar Poema de Chile. ${ }^{4}$ Luego de la muerte de la poeta en enero de 1957, Dana comenzó a proyectar la publicación de los inéditos que poseía, solicitando fondos a diversas instituciones y estableciendo contacto con Alone (el crítico chileno Hernán Díaz Arrieta). ${ }^{5}$ En cartas enviadas a Alone durante 1957, la albacea de la poeta expresa su deseo de publicar Poema de Chile y Lagar II para lo cual solicita la ayuda del crítico. ${ }^{6}$ Alone aceptó la invitación, y colaboró en la primera edición del Poema de Chile (1967); sin embargo, con respecto a Lagar II, el crítico argumenta a Dana:?

-no solo literarias- a partir del examen minucioso de las sucesivas redacciones que esta tuvo. A través de esta clase de estudio se puede conocer "el interior de su composición, las intenciones del autor, sus procedimientos" (Pastor Platero, 2008, p. 11). No aspira, como la filología clásica, a fijar un texto "definitivo" o "completo", sino a conocer los procesos creativos de un autor. Para ampliar la información sobre esta línea teórica, cfr. Bellemin-Nöel (1972), Grésillon (1994), Biasi (2011), Blecua (2012), Vauthier y Gamba (2012).

4 Entre 1967 y 1991 se publican algunos textos que contienen poesía inédita mistraliana, pero no constituyen poemarios completos de Mistral. En su orden: el número especial dedicado a Mistral en la Revista Orfeo (1967); el estudio de Esther de Cáceres que prologa las Poesías completas de Mistral editadas por Aguilar (1968); el ensayo Una mujer nada de tonta, de Roque Esteban Scarpa (1976); la antología Reino: Gabriela Mistral (poesía dispersa e inédita, en verso y prosa), de Gastón von dem Bussche (1983); el ensayo El otro suicida de Gabriela Mistral, de Luis Vargas Saavedra (1985); el volumen Gabriela Mistral, nuevas visiones, de la Universidad Austral de Chile, que contiene estudios e incluye inéditos (1990, pp. 13-20). Asimismo, se debe mencionar la reedición de Poema de Chile en 1985, con prólogo de Jaime Quezada, pues en un anexo a la obra añade poemas que no aparecían en la primera edición.

5 En los archivos digitalizados existen cartas dirigidas a Dana por parte de la John Simon Guggenheim Memorial Foundation (Leighton, 15 de mayo, 1957) y de la Bollingen Foundation (Russ, 22 de mayo, 1957), que responden negativamente a la petición de fondos para el trabajo que realizaría Alone con los inéditos. En cambio, la Fundación Rockefeller resolvió apoyar económicamente el traslado del crítico hasta Nueva York y su estadía en esa ciudad; así lo informa Dana a Alone, en carta fechada el 8 de septiembre de 1957.

6 En una carta que data del $1^{\circ}$ de febrero de 1957, Dana solicita colaboración de Alone para editar el "Recado de Chile"; en una carta posterior, del 12 de mayo del mismo año, le solicita hacerse cargo de Lagar II.

7 Alone no fechó esta carta, escrita en una esquela del Hotel Saint George de Nueva York; sin embargo, tanto su contenido como las fechas de otras misivas de respuesta a Doris Dana de 1957 permitieron a los especialistas de la Biblioteca Nacional de Chile datarla tentativamente en dicho año. 
Si a "Lagar" lo titulas "Lagar II" [los críticos] dirán que se trata de los desperdicios de "Lagar I", lo que Gabriela rehusó publicar en vida, etc. Gabriela, tú y la Fundación [Rockefeller] sufrirían grandes perjuicios. Te aconsejo ponerle, como se acostumbra, el título de uno de los poemas de la colección. Por ejemplo éste [sic] tan hermoso "Electra en la Niebla". ¿Comprendes el efecto? "Electra en la Niebla", por Gabriela Mistral. Verían el libro inédito, desde luego. Y, después iqué protesta contra la idea de la muerte de Gabriela! Es como decir, no ha muerto, está solamente "en la niebla". (Alone, s. f.) ${ }^{8}$

La estrategia sugerida por Alone consiste en desvincular los poemas inéditos de Lagar de 1954, confiando en la poca sagacidad de los críticos, los que se dejarían llevar por el título, según su argumentación. Además, el estudioso apunta a relacionar el texto con la contingencia de la muerte de la poeta, vale decir, a aprovechar el contenido del poema para transformar a su autora en un mito, la que a través de sus versos consigue trascender la muerte. Quizás esta opinión de Alone influyó para que Lagar II no fuese publicado por Dana en esta época. No obstante, en los manuscritos digitalizados de Mistral, ha quedado huella del trabajo del crítico; el archivo "Cuaderno, versión de Lagar" (56 hojas) corresponde a la versión que Alone organizó. En la portada, escrita a mano, se aprecia que el título "Lagar" fue borrado y reemplazado por "Electra en la niebla".

El índice de este archivo incluye cuarenta y seis poemas, pero en realidad aparecen treinta y dos poemas mecanografiados, el último de los cuales, "Raíces", no está incluido en el índice. ${ }^{9}$ Alone le asignó un número a cada ronda; es posible que este listado fuese provisorio,

8 En las Referencias se cita cada manuscrito con su respectivo número de ID del Archivo Gabriela Mistral de la Biblioteca Nacional Digital de Chile.

9 A continuación se transcribe el índice (páginas 4-8); los títulos subrayados son los que efectivamente figuran mecanografiados en el archivo: Electra en la niebla, El huésped, Despedida del viajero, La gruta, Vamos a bailar la ronda, Ronda de la hierba (1), Ronda del mar (2), Ronda de las manzanillas (3), Invitación a la música, El tiempo, ¿A qué...?, Poema de los hebreos, Un extraviado, Reseda, Montaña y Mar, Montañas, Lavanda, Arcángeles, Altos hornos, Recado sobre una copa, Nocturno, Vine de Oscura Patria, Padre veedor, La remembranza, Espíritu santo, Ronda de la zafra (4), Ronda del azúcar (5), Acción de gracias, Pascua, La trocada, Madre bisoja, La cabelluda, El mar, Lugar

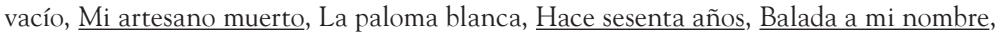
Convite a la danza, La llama y yo..., Antígona, El viento oscuro, Ruta, La liana, El santo cactus, Monte Orizaba, Raíces. 
pues los poemas no están distribuidos en secciones. Probablemente Alone proyectaba la sección "Rondas" y pretendía reorganizar los textos; $;^{10}$ en todo caso, su trabajo permaneció inconcluso, hasta que en 1965 se encontró nueva información sobre los inéditos que incidió en la edición de Lagar II.

Ese año, la profesora Magda Arce de la Universidad de Chile descubrió nueve baúles con documentos de Mistral en la residencia de la poeta en Santa Bárbara, California. ${ }^{11}$ Arce extrajo de los baúles ciento cincuenta documentos para publicarlos ${ }^{12}$ y contactó a Doris Dana, quien no conocía la existencia de ese material. Con el propósito de microfilmarlos, Dana se llevó los baúles, los cuales, de acuerdo con la versión de Arce, contenían setenta mil hojas. Durante 1980 y 1981, este proceso se llevó a cabo en la Biblioteca del Congreso en Washington, con el auspicio del Gobierno de Chile y la Organización de Estados Americanos (OEA). El profesor Gastón von dem Bussche y Doris Dana trabajaron en la catalogación de los documentos, que permanecieron en Washington hasta que en la década del noventa el Gobierno de Chile adquirió cuarenta y tres microfilmes..$^{13}$ La publicación Lagar II se obtuvo "del rollo o reel N. 1", como lo anota Pedro Pablo Zegers en la introducción a la obra (1991, p. 15).

10 En el índice de Alone faltan los poemas de Lagar II "Cuando murió mi madre", "La contadora", "La que aguarda", "Dos trascordados", "Golondrinas del yodo", "Al mar", "Aserradero", "Pascuas" en sus dos versiones -aunque figura un poema llamado "Pascua",-, "Ronda de la creación" y "Canción de las niñas catalanas". De "El viento oscuro" aparece la primera versión y dieciocho versos de la segunda. No sabemos si los poemas "El santo cactus", "El mar", "Montañas", "Ronda de la zafra", incluirían sus dos versiones. Con respecto a los "Nocturnos", los tres Nocturnos de Lagar II están consignados, pero son versiones diferentes a las publicadas. El poema "Balada de mi nombre" se denomina en este índice "Balada a mi nombre".

11 En el estudio Proyecto preservación y difusión del legado literario de Gabriela Mistral (1993), Magda Arce relata que en el garaje de la casa encontró baúles con las iniciales de la poeta rotulados con la nota "To be shipped to Chile".

12 Con la colaboración de Eugenio García Carrillo, Magda Arce publicó Gabriela Mistral y Joaquín García Monge: una correspondencia inédita (1989).

13 En los archivos digitalizados por la Biblioteca Nacional se encuentra la correspondencia entre Gastón von dem Bussche y Doris Dana, cuya lectura permite saber que von dem Bussche contactó a Dana para compartir su plan de catalogación de los papeles inéditos de la poeta (von dem Bussche, 22 de mayo de 1979), y que esta accedió, para lo cual inició gestiones con la OEA. Según las fechas de las cartas y de la prensa de la época del archivo de la Biblioteca Nacional de Chile, pienso que von dem Bussche estuvo presumiblemente entre septiembre de 1980 hasta junio de 1981 en Washington. 
El manuscrito de Lagar II fue catalogado en la Biblioteca Nacional como "Archivador 9". Son 318 páginas con los índices de las secciones y los poemas transcritos, de los que treinta y siete poseen dos copias, uno posee tres copias, y veintiséis poseen solo una; más que de copias, la mayoría de los casos constituyen versiones distintas. Hay dos tipos de hojas: unas que son de color amarillento o café, a las que es probable que los años les hayan dado este color, y otras rosadas, las que son las versiones "en limpio" de los cambios efectuados a lápiz por la poeta en las hojas café y algunos cambios menores realizados por Doris Dana. También se incluyen notas de Dana que consignan correcciones por hacer, dudas u opiniones que le surgían al momento de realizar las transcripciones.

Otro archivo relevante es "Índices y listados de Lagar I y II" (29 páginas), debido a que en este se encuentra el índice con el que se ordenó Lagar II (pp. 14-16). Este manuscrito consiste en un conjunto de hojas sueltas que contienen diversos listados de poemas; ${ }^{14}$ en seis de estos listados -con poemas de Lagar (pp. 4-12)- aparecen diecisiete poemas de Lagar II..$^{15}$ El índice de la página 8 es el único fechado con la nota "Gabriela separó el 23 de mayo de 1954". Los índices de Lagar II son tres (pp. 13, 14-16 y 18-19); es evidente que el que se utilizó es el más completo y se corresponde con el material del "Archivador 9". Salvo la fecha que se menciona, las demás hojas de ambos archivos carecen de fecha, lo que dificulta aún más el trabajo con estos documentos.

14 Es evidente que las hojas de este archivo provienen de distintas épocas; son de materiales distintos, hay hojas escritas a mano con distintas caligrafías, y otras están mecanografiadas. La primera hoja posee una nota a mano que dice "Elegidas para ir a Pittsburgh", lo que podría ser el índice de una lectura poética, pues los textos pertenecen a Desolación, Ternura, Lagar y Poema de Chile; la página 3 también es una miscelánea de poemas provenientes de Desolación, Ternura, Poema de Chile, además de dos inéditos, "Ronda de los olores", publicado en Baila y sueña (2011) y "Hay dos"; las páginas 20-21 contienen un índice que abarca poemas de Desolación y Lagar. Es extraña la ausencia de poemas de Tala en estos índices misceláneos, así como también la presencia constante del poema "Ronda del fuego" de Ternura en los referidos listados: ¿se preparaba una antología? Las siguientes hojas son índices tentativos de Lagar, pero también incluyen poemas aún inéditos. El índice que se utilizó para Lagar II está mecanografiado y tiene notas holográficas.

15 Estos textos son: "Mi artesano muerto", "Despedida de viajero", "Lugar vacío", "Madre Bisoja", "La cabelluda", "Reseda", "Lavanda", "Santo cactus", "La trocada", "La contadora", "Altos hornos", "Espíritu Santo", "La liana”, "Vine de Oscura patria”, "De tanto andar (La gruta)", "La que aguarda" y "Los [idos?] trascordados". 
Lagar II se divide en doce secciones, de acuerdo con el índice encontrado. Como los editores señalan en la introducción, solo se omitió del índice la sección "Sin clasificar", que reúne once poemas, de los cuales "Niño siciliano", "Había un mocetón blanco", "La otra madre" y "Los Otros", se editaron en Almácigo (2008), mientras que "Niños" y "Canción de Cuna" en Baila y sueña (2011).

Como lo explica Zegers en la introducción a Lagar II, esta obra póstuma formaba parte de Lagar (1954), pero por consejo de los editores de este último, Mistral dividió el poemario a causa de su extensión (Zegers, 1991, p. 15). El estudioso Grínor Rojo (1997) discrepa de la opinión de Zegers, que se fundamenta en la opinión de Gastón von dem Bussche, como el mismo Zegers reconoce en el texto introductorio. Rojo asevera: "la tesis de que haya habido un solo manuscrito dispuesto ya para ir a la imprenta en 1954 es un tanto arriesgada y se contradice con el estado de elaboración aún no resuelta en el que nosotros hallamos muchos de los poemas que integran Lagar II" (1997, p. 392).

De acuerdo con los índices revisados, es notorio que la escritora seleccionó para Lagar (1954) los textos que estaban concluidos, desestimando algunos de los poemas publicados en Lagar II; de esta manera, es posible considerar a este un vestigio de Lagar, que no alcanzó a depurarse. Es decir, lo que estaba conformado en 1954 era el "proyecto Lagar", no el poemario "dispuesto para ir a la imprenta", como bien señala Rojo.

Asimismo, el estudio de los manuscritos digitalizados por la Biblioteca Nacional no confirma que el índice de Lagar II sea de autoría de Mistral; Ana María Cuneo, integrante de la comisión que preparó la edición, reconoce en un artículo sobre el poema "El tiempo" de Lagar II que "no es posible establecer con certeza [la] filiación" de este índice (Cuneo, 1989, p. 47). En este sentido, el archivo elaborado por Alone es un indicio de que Dana no poseía ningún índice preparado por la poeta.

Si bien existe un documento ("Archivador 9") con el material organizado de acuerdo con este índice, y cuyas hojas poseen correcciones realizadas por Mistral, no es probable que la poeta interviniera en el orden de los poemas ¿Podría este índice provenir de los baúles encontrados por Magda Arce y, como Dana los obtuvo 
en una fecha posterior al trabajo realizado con Alone, el crítico los desconocía?, o ¿el índice de Lagar II fue elaborado por Doris Dana y Gastón von dem Bussche?

Si el índice provino de los documentos encontrados por Arce, es difícil que Dana lo desconociera hasta ese entonces, puesto que se trata de la organización de poemas no publicados, trabajo del que ella se encargaba; por ello, me inclino a pensar que, tanto este índice como el "Archivador 9", fueron elaborados por von dem Bussche y Dana a principios de los ochenta, y adjuntado a los documentos inéditos enviados a Chile.

En una entrevista concedida luego de su regreso a Chile, después de trabajar por diez meses junto a Dana en la Biblioteca del Congreso en Washington, von dem Bussche declara: "Doris ya encontró financiamiento para publicar un segundo tomo de 'Lagar' con las poesías que yo seleccioné de todos esos manuscritos inéditos" (Delpiano, 1982, p. E). Esta declaración corroboraría la hipótesis señalada; no obstante, cabe destacar que aparte de las afirmaciones de von dem Bussche, no se ha encontrado en el curso de esta investigación otro documento que confirme sus palabras, por lo que no existe certidumbre absoluta. ${ }^{16}$

Tampoco hay certeza de que Mistral pretendiera publicar Lagar II; en la introducción a esta obra se argumenta que en las Poesías completas de Mistral, publicadas por Aguilar en 1958, el poemario Lagar se titula "Lagar I", lo que resulta revelador pues Mistral elaboró junto a Margaret Bates este volumen. ${ }^{17}$ Sin embargo, a la muerte de la poeta, la obra que se denomina Lagar II correspondía a poemas sueltos e incompletos; ¿le faltó tiempo o salud a la escritora para finalizarlo?, ¿o simplemente desestimó este proyecto?

16 Recuérdese que von dem Bussche formó parte de la comisión de Lagar II, por lo que resulta curioso que, si el índice fue organizado por él, no haya dado a conocer esta información al resto de la comisión.

17 Poesías completas tiene cuatro ediciones: 1958, 1968, 1970 y 1976. En la primera edición, las introducciones fueron preparadas por Julio Saavedra Molina y Dulce María Loynaz; en las tres últimas ediciones el estudio preliminar pertenece a la uruguaya Esther de Cáceres. 
La mayoría de los textos reunidos en Lagar II no fueron concluidos ni aprobados por la poeta. Es así como se evidencian correcciones por realizar, estrofas incompletas, anomalías métricas o rítmicas, entre otros aspectos. Debido a esta disparidad entre los poemas, Ana María Cuneo propuso conformar una sección con los poemas aprobados por Mistral y otra con los fragmentarios, con el objetivo de proyectar una edición para el público general y una segunda entrega destinada a especialistas, en la que se incluirían los textos fragmentarios.

Gastón von dem Bussche era partidario de la idea de Cuneo, como señala en su artículo "Introducción a una lectura poética de Lagar II" (1992, p. 35). Pese a ello, la comisión se inclinó por conservar el índice mencionado. ${ }^{18}$ Por tanto, los editores debieron implementar un sistema de notas al pie para comunicar al lector las ambigüedades, carencias o vacilaciones de los originales. Además de las notas, se utilizó el asterisco para indicar los textos que la autora rotuló "por corregir" sin especificar el aspecto preciso a enmendar.

\section{Recepción de Lagar II en Chile}

La publicación del texto causó polémica entre los académicos; de estas opiniones llama la atención la de Luis Vargas Saavedra, por el papel que este jugaría años más tarde en la publicación de la poesía inédita compilada en Almácigo (2009) y Baila y sueña (2011). En el diario El Mercurio, Vargas Saavedra manifiesta su duda acerca de lo señalado por Zegers en el prólogo de Lagar II con respecto a que los poemas de este último libro formaran parte de Lagar. Asimismo, el crítico se muestra en contra de la edición de textos inacabados de la poeta, además de criticar el trabajo de los editores:

18 Cuneo hace referencia a este episodio en su ensayo Para leer a Gabriela Mistral (1998), donde reflexiona sobre la poética de la escritora a través de su obra completa, salvo Lagar II. Así justifica su decisión de excluir el poemario póstumo de su análisis: "La no inclusión de Lagar II responde a convicciones profundas, que surgieron en mí cuando trabajé en la Biblioteca Nacional en la preparación de dicha publicación. El estudio cuidadoso de los microfilms, me permite afirmar que de los poemas publicados solo trece estarán probablemente concluidos. Los restantes son materiales en evidente proceso de elaboración y debían publicarse tal cual estaban en los manuscritos. Mi criterio no prevaleció en la publicación" (1998, p. 13). 
A pesar del notable esfuerzo por editar esos materiales de taller -poemas en estado de conato, tanteo y refundición- el resultado es imperfecto: no se ha transcrito ceñidamente el microfilme de los borradores, y se colocan notas superfluas. Mejor hubiera sido atender a las razones de Ana María Cuneo (mencionadas por Zegers) y preparar una edición para especialistas, donde se mostraran todas las versiones y variantes, con sus tachaduras y propuestas, la poesía en estado de construcción. (Vargas Saavedra, 1991, p. 6, subrayados en el original)

Cabe señalar que en los poemarios póstumos Almácigo (2009) y Baila y sueña (2011), editados por Vargas Saavedra, no se incluyen indicaciones acerca de variantes o tachaduras y algunos de los textos publicados no corresponden a poemas, sino a estrofas desechadas de textos ya publicados, como el poema "Cajita de Olinalá II" de Baila y sueña (Mistral, 2011, p. 15). ${ }^{19}$ Rescato lo señalado por Vargas Saavedra con respecto a que existen versiones de algunos poemas de Lagar II publicados en vida por la autora en revistas. Jaime Quezada especifica tres de ellos, y expresa la necesidad de una edición crítica de Mistral:

Varios de estos textos se publicaron, el año 42, el año 46, en La Nación de Buenos Aires ("La trocada"), El Mercurio de Santiago ("Golondrinas del yodo"), y una antología francesa ("Mi artesano muerto"). También la revista Orfeo (1967) y el propio Gastón Von dem Bussche (Reino, 1983) recogen un buen número de estos poemas. Interesante hubiese sido, entonces, una edición crítica y referencial como un todo de la obra inédita y última de la autora. (1992, p. 34)

Quezada también manifiesta la percepción de estos poemas como de menor "altura y proyección" que la obra anterior de Mistral, y agrega que existen poemas de Lagar II, como "Paloma blanca" y

19 "Cajita de Olinalá II" corresponde a fragmentos de estrofas descartadas por la poeta durante el proceso de escritura del poema "Cajita de Olinalá" del libro Tala, que el editor del libro ordenó para conformar este texto; por lo tanto, sería discutible su condición de poema inédito. Esta aseveración puede comprobarse al revisar los manuscritos de "Cajita de Olinalá", disponibles en la Biblioteca Nacional Digital de Chile; los manuscritos AE0014732 y AE0013736 son similares al texto de Tala, pero los manuscritos AE0013272, AE0018413, Cuaderno 31 (AE0013059) y Cuaderno 180 (AE0015283) contienen estrofas tachadas que se recuperaron en "Cajita de Olinalá II". Vargas Saavedra señala en el prólogo de Baila y sueña: "En cuanto a 'Cajita de Olinalá II', el número romano indica su vínculo con la 'Cajita de Olinalá' que viene en Tala. Publicándola se provoca un conato de ensamblaje, que consistiría en sumar ambas versiones para obtener un poema más extenso y de la misma calidad" (2011, pp. 6-7). 
"Montaña", que se confunden con textos de Poema de Chile. ${ }^{20}$ Diarios como El Nortino de Iquique, La Mañana de Talca y Las Últimas Noticias de Santiago anunciaron y reseñaron Lagar II. En este último medio, se entrevistó a Pedro Pablo Zegers y Ana María Cuneo, quienes declararon que solo trece poemas estaban concluidos, ${ }^{21}$ a lo que Cuneo agrega que es imperativo realizar una edición crítica de los textos:

La profesora Cuneo, no obstante, considera que Lagar II debe ser leído "con posterioridad a un conocimiento profundo de la obra lírica publicada por voluntad de Mistral. Al igual que Poema de Chile, este texto debe ser objeto de una edición crítica realizada por especialistas idóneos". (Las Últimas Noticias, 1991, p. 27)

La pregunta es por qué aún no existe una edición crítica de Lagar II, a más de veinte años de su publicación..$^{22}$ Los estudios críticos

20 Como comenta Quezada, Gastón von dem Bussche editó en Reino (1983) poesía y prosa publicada anteriormente en revistas, y algunos textos inéditos. Los poemas de Lagar II que se publicaron en este volumen son: "Mi artesano muerto" y "La liana", que provienen de la Antología de Gabriela Mistral (Colección Du Monde Entier. París, Gallimard, 1946); "Electra en la niebla", publicado como inédito en la Revista Orfeo (1967), "Despedida de viajero", cedido por Doris Dana a von dem Bussche. "¿A qué?", "Hace sesenta años", "Montañas" (en Lagar II equivale a "Montañas I"), "Balada de mi nombre", "La contadora" y "Acción de gracias", provienen de la introducción escrita por Esther de Cáceres a las Poesías completas de Mistral, editadas por Aguilar. En el prólogo a Reino, von dem Bussche cita la cuarta edición de las Poesías completas como fuente de estos poemas. Por nuestra parte, la revisión de las tres últimas ediciones de las Poesías completas nos permitió comprobar la presencia de estos textos, a los que agregamos el "Nocturno I", como lo denomina Esther de Cáceres o "Nocturno VI" (Lagar II) y "La liana", también presentados como inéditos en el volumen de Aguilar. Esther de Cáceres señala en su introducción que los ocho poemas inéditos le fueron proporcionados por Doris Dana. El cotejo entre la edición de estos poemas en Reino y en la introducción a las Poesías completas evidencia que hay diferencias en los textos "La liana", "La contadora", "Acción de gracias" y "Balada de mi nombre"; en los dos últimos textos, las diferencias son muy leves. Asimismo, el cotejo entre la versión de "Nocturno I" (Poesías completas) y "Nocturno VI" (Lagar II) también arroja divergencias.

21 Cuneo enumera estos poemas en un artículo, aunque reconoce que "no es raro encontrar también en los textos aprobados rasgos que muestran un proceso creativo no concluido" (1990, p. 53). Los trece poemas son: "Antígona", "Madre Bisoja", "La trocada", "Reseda", "Espíritu Santo", "La remembranza", "Ronda de la zafra 2", Ronda del mar", "Vamos a bailar la ronda", "Despedida de viajero", "Un extraviado" / (Nada), "El huésped", e "Invitación a la música" (Cuneo, 1990, p. 53).

22 Un aspecto extratextual que influyó en la escasez de ediciones de distintas obras póstumas fueron las relaciones un tanto conflictivas de la albacea de Mistral, Doris Dana, y los estudiosos chilenos de la obra mistraliana. En una entrevista con la Revista Hoy, Pedro Pablo Zegers señala que Doris Dana se oponía a cualquier publicación de nuevas obras de Mistral, sin que se supieran las razones (Robino, 1991, p. 43). La actitud de Dana es extraña si se piensa en la invitación que realizara a Alone y posteriormente a Gastón von dem Bussche; al parecer, Dana solo confió en ellos. A la muerte de Dana 
sobre Lagar II son escasos, situación que podría relacionarse con esta necesidad editorial de la obra póstuma mistraliana, señalada por los estudiosos citados; la polémica en torno a Lagar II y a los demás poemarios póstumos de Mistral ¿podría haber menguado el interés de la crítica por estos materiales? ${ }^{23}$.

\section{El poema "Convite a la danza": versiones preliminares y ediciones}

En la misma línea de Grésillon (1994), Pierre de Biasi define dossier de génesis como "conjunto, clasificado y transcrito, de los manuscritos y documentos de trabajo conocidos que se refieren a un texto cuya forma ha alcanzado, desde el punto de vista de su autor, un estado de redacción avanzado, definitivo, o casi definitivo" (2008, p. 117). De acuerdo con estos planteamientos, examinaremos el dossier de génesis del poema que inicia Lagar II, "Convite a la danza", considerando los manuscritos y las ediciones que se han hecho de ellos.

El mencionado poema posee seis estrofas, veinticuatro versos octosílabos y rima asonante en los versos pares, que finalizan en palabras agudas, mientras los impares terminan en palabras graves. En el texto, Mistral poetiza una invitación dirigida tanto a elementos de la naturaleza como a seres humanos; a estos últimos los conmina a danzar incluso si han "perdido todo". 24

En el "Archivador 9" se encuentran dos copias de "Convite a la danza", la primera en hojas café (pp. 2 y 3), y la segunda en una hoja rosada (p. 4); los editores se basaron en la primera, incorporando

(2006), su heredera Doris Atkinson entregó todos los documentos de Gabriela Mistral a la Biblioteca Nacional de Chile.

23 Menciono los estudiosos que se han dedicado a Lagar II: Grínor Rojo (1997, pp. 391-438) presenta los temas fundamentales de los poemas; Lorena Garrido (2012) lo incluye en su ensayo sobre la metapoesía mistraliana. El resto de los críticos abordan poemas aislados, como Ana María Cuneo (1989), Sergio Sandoval (2012), Dieter Oelker (2011), y María Cecilia Graña (2014).

24 Grínor Rojo comenta sobre el poema que este "recoge frases y hasta versos enteros de 'La bailarina' de Lagar" (1997, p. 396), atribuyéndolo a la relación entre las imágenes de la danza y el discurso de la libertad femenina, que en la poesía de Mistral se encontraría en el retorno a la infancia. Por su parte, Lorena Garrido Donoso interpreta la danza en el poema como una imagen metatextual: "Esta 'danza' le permite al que la baile alcanzar plenitud y trascendencia; calmar 'esta ansiedad, esta sed' presente en el mundo terrenal [...] La poesía permite superar este límite siempre que se haga una entrega total” (2012, p. 102). 
los cambios estipulados con lápiz; la segunda copia corrige algunos cambios hechos en la hoja café -como el intercambio en el orden de las estrofas 4 y 5, cambio incluido en Lagar II-, y agrega signos de exclamación al verso 12 , lo que no aparece indicado por la poeta en la otra copia. Aparte de la variante mencionada por los editores de Lagar II en la nota 2 de pie de página, ${ }^{25}$ las otras diferencias entre estas dos copias se refieren a que la poeta oscilaba entre los verbos "danzar" y "bailar" en las distintas estrofas. El poema publicado corresponde de manera fiel al original, y la poeta lo había aprobado, como lo indica un "Sî" en grafito al inicio del manuscrito. ${ }^{26}$

Es importante señalar que en Almácigo y Baila y sueña fragmentos de versiones preliminares de este poema fueron presentadas como poemas inéditos. Aparte de las copias del "Archivador 9", existen seis manuscritos digitalizados que corresponden a versiones preliminares de "Convite a la danza", ninguno fechado. Dos de los seis manuscritos llevan por título "Convite a la danza", uno con el título completo mecanografiado (AE0013783), y el otro con la palabra "Convite" mecanografiada al cual la poeta le agrega "a la danza" con lápiz (AE0013782). Ambos manuscritos son versiones preliminares del poema en los que se observan leves cambios en relación con la versión del "Archivador 9".

Los cuatro manuscritos restantes son anteriores a estas dos versiones, lo que es posible constatar por el nivel de elaboración de los dos manuscritos con el título de "Convite a la danza"; es decir, las tachaduras y las correcciones de los cuatro manuscritos se materializan en las últimas versiones. En estos manuscritos preliminares el poema se titula "Convite"; el más extenso, de 11 hojas, fue la base de la publicación de la ronda "Convite" de Baila y sueña (2011, pp. 20-21),

25 "En el verso 'esta ansiedad, esta sed', lo propuesto primero por ella era: 'este límite, esta sed'. No habiendo indicación respecto a que su duda se refiera a 'límite' o 'sed', optamos por 'ansiedad', lo que mantiene la rima de los versos pares, forma de expresión común en G. Mistral" (1991, p. 23).

26 En la versión ordenada por Alone (Archivo AE0015394, p. 46) el poema no está dividido en estrofas, y las estrofas 4 y 5 de la versión de Lagar II están intercambiadas. Otros cambios son los siguientes: en los versos 2, 10 y 19 de la versión de Alone se observa una coma al finalizar cada verso; en la versión del "Archivador 9" publicada en Lagar II, los versos 2 y 10 llevan punto y coma, y el verso 19, ningún signo. Por último, el verso 7 de la versión de Alone es: "las hierbas heridas se alzan" y el de Lagar II es "la hierba herida se alza". 
y del breve texto "La sabuesa Muerte", de Almácigo (2009, p. 215). Si se comparan los poemas "Convite a la danza" y "Convite", de Baila y sueña, se encuentran similitudes. Confrontemos el poema aprobado por Mistral en la columna izquierda (Lagar II) con algunas de las estrofas de "Convite" (Baila y sueña) en la columna derecha:

Convite a la danza (Lagar II)

1 Romped la marcha de hierbas Romped la mancha de hierbas

2 que la hierba no rompéis; que las hierbas no rompéis,

3 la muy amante retorna las hierbas amantes vuelven

4 y la danzáis otra vez. y las bailáis otra vez.

(Estrofa 6 de "Convite")

5 Romped cebadas y trébol Romped cebadas y trébol,

6 que ninguno romperéis: que ninguna hierba rompéis.

7 la hierba herida se alza Hierbas rotas se levantan

8 y la bailáis otra vez. y las bailáis otra vez.

(Estrofa 10 de "Convite")

9 Bailad los pastos floridos Bailad los pastos floridos

10 y los que han de florecer; o que están por florecer,

11 los trigos que ya segaron, los trigos que ya segaron

12 los no sembrados también. los no sembrados también.

(Estrofa 5 de "Convite")

13 Quebrad esta nuez del mundo, Quebrad esta nuez del mundo, 14 esta ansiedad, esta sed. que rota la dejaréis.

15 Cabello y brazos al viento, Abrid el cielo cantando

16 bailad como que voléis. y en cielo abierto dancéis.

(Estrofa 12 de "Convite")

17 Haced como que soltaseis

Bailad como que soltárais

18 vuestra vida de una vez; vuestra vida de una vez

19 y con son y ritmo eternos $\mathrm{y}$ con un aire de eternos

20 la danza eterna bailéis. perdidamente bailéis.

(Estrofa 9 de "Convite") 
21 Bailad como que soltaseis

22 cuerpo y alma de una vez.

23 y si habéis perdido todo

24 mejor que nunca dancéis.
Bailad como que soltárais todo el mundo de una vez y cuando os llamen los que duermen, mejor que nunca bailéis.

(Estrofa 11 de "Convite")

Es evidente que las estrofas citadas del poema editado en Baila y sueña corresponden a versiones preliminares de las seis estrofas de "Convite a la danza". La versión de "Convite" que se editó en Baila y sueña posee doce estrofas obtenidas de la versión preliminar de once páginas del poema editado en Lagar II. Estas estrofas de "Convite" fueron desechadas por Mistral, por lo cual considero que el poema no pertenece al grupo de poemas inéditos, como se presenta en el volumen Baila y sueña, sino que es un vestigio de un borrador incipiente. Para comprobar lo dicho, examinaré los cuatro manuscritos de las versiones preliminares de "Convite a la danza", titulados "Convite", desde el más breve -porque es el que más se acerca a la versión final- hasta el más extenso.

El manuscrito más sucinto consiste en dos hojas mecanografiadas con algunos cambios en lápiz (AE0013781). En el extremo superior derecho hay unas notas con lápiz: "Desvarío" "archivar", que lo ubica en la sección que inicia Lagar y Lagar II. El contenido de estas hojas es el poema "Convite a la danza" de Lagar II, que en esta versión cuenta con siete estrofas y una tachada, ordenadas tentativamente, pues la poeta enumeró a la izquierda las estrofas con lápiz: cuatro estrofas tienen dos números, uno borrado y tachado y el otro escrito encima; del orden tentativo de este manuscrito se mantuvo en la versión final el de las estrofas 1,2 y 6 . Además, en la segunda hoja aparecen dos estrofas que finalmente se desecharon, y que son variantes ${ }^{27}$ de las estrofas 2 y 12 de "Convite", de Baila y sueña.

El siguiente manuscrito posee tres hojas mecanografiadas con correcciones hechas con lápiz (AE0013780). En esta versión, el

27 En el contexto de este trabajo, se entienden por variantes "las correcciones, las vacilaciones, las propuestas alternativas" (Marchese y Forradellas, 2000, p. 416) en el caso de un verso o de una estrofa en concreto, distinguiéndose de este modo del concepto de versión, que utilizo para designar propuestas alternativas que atañen a un poema en su totalidad. 
poema posee doce estrofas de cuatro versos (tres de ellas están tachadas), a excepción de una de seis versos, cuyos dos primeros son una versión preliminar de la estrofa 4 de "Convite a la danza" y los cuatro restantes conforman una variante de la primera estrofa del poema "Convite" de Baila y Sueña. De las otras once estrofas, se verifica que ocho son variantes de las estrofas de "Convite a la danza", dos son variantes de las estrofas 2 y 7 de "Convite" (Baila y sueña), y una es la estrofa número ocho de este último poema, que está tachada en este manuscrito (hoja 2, primeros versos).

El próximo manuscrito también posee tres hojas mecanografiadas, con marcas de lápiz (AE0013779). En esta variante, el poema cuenta con dieciséis estrofas, dos de ellas incompletas además de tachadas y una de cinco versos tachada; la mayoría de los versos poseen numerosas variantes. Ninguna de las estrofas corresponde a las de la versión final de "Convite a la danza", pero reconozco en este manuscrito seis estrofas que son versiones preliminares de las estrofas 1 a 5 de este poema. Nueve estrofas de las dieciséis son variantes de alguna de las estrofas de la edición de "Convite".

Por último, el original más extenso consiste en once hojas escritas a mano por Mistral, con tachaduras (AE0018419). El editor del poema "Convite" extrajo las tachaduras y omitió las hojas 2 y 6, cuyos versos se editaron con el título "La sabuesa Muerte" en Almácigo. Cabe preguntarse la razón de esta división, y la unión de hojas tan distantes en un poema; al respecto, se debe señalar que las hojas 2 y 6 corresponden a las únicas páginas escritas en el reverso del documento; vale decir, que la hoja 2 es el reverso de la hoja $1, y$ la hoja 6 lo es de la $5 .^{28}$

Contrastemos ahora el poema "Convite" de Baila y sueña en la columna izquierda, con el manuscrito de Mistral en la columna derecha. Se omiten en la transcripción del original las hojas 2 y 6 por los motivos mencionados: ${ }^{29}$

28 Agradezco la gentileza de Pedro Pablo Zegers que me permitió observar el manuscrito original en el Archivo de Gabriela Mistral en la Biblioteca Nacional de Chile y constatar esta afirmación.

29 La transcripción diplomática sigue las cuatro convenciones que se muestran a continuación. Inconcluso en el original: [...]; separación entre variantes de versos: /; tachaduras: abe; paréntesis en el original: ( ). 
CONVITE (pp. 20-21)

Bailad las cuatro estaciones los amigos y el rondel. Cabellos y brazos al viento, bailad como que voléis.
Bailad si vienen las flautas, si no llegan, lo mismo bailéis. Bailad si vienen los otros, y si no, bailad también.

\section{CONVITE (Manuscrito)}

\section{Hoja 1}

las cuatro estaciones

1 Bailad el año y el día, y el año [...]

los amigos y el rondel

en ruedo, en anillo, en [...]

Cabellos y brazos al viento

bailad como que voléis.

2 Bailad si vienen las flautas sonando por el plantel cuando [...] y si se rompen las flautas, ${ }^{30}$ escuchándolas bailéis como que suenen [...]

\section{Hoja 3}
querer
ta Antrériea
Bailad los niños de peseadores
del mundo
de mineros y de
que me tengo de [...]
si no supierais el baile,
\_y si no sabéis el baile
bailad como si sabéis.
\_Bailad igual que si sabéis.
3 Bailad si vienen las flautas;
si no, lo mismo bailéis, ${ }^{31}$
Bailad si vienen los otros;
si no, bailad también ${ }^{32}$

30 Variantes del verso que se anotan en la parte inferior de la hoja: "Pero si se rompen". Se tacha "rompen" y se reemplaza por "cascan". Se tacha "pero". "Si se cascan, si se rompen". Se perciben borrones hechos con goma.

31 Se tachó parte del verso; originalmente decía: "si no llegasen igual bailéis". "Llegasen” se reemplaza por "llegan", que también se tacha y se escribe "lo mismo" en su reemplazo.

32 Originalmente, la poeta escribió "si no llegan, bailad también". Omite el verbo "llegar"; al igual que en el caso de la nota anterior, se hace más escueta la expresión. 


\section{Hoja 4}

Bailad los soles y las nieves, lo que habéis y no tenéis

el día al venir la noche,

la noche al amanecer.

Bailad cosas que no bailan, y a son y son las traeréis. Si los llamados no vienen todavía mejor bailéis.

Bailad los pastos floridos o que están por florecer, los trigos que ya segaron los no sembrados también.

Romped la mancha de hierbas que las hierbas no rompéis, las hierbas amantes vuelven

y las bailáis otra vez.

Bailad el cuerpo y el alma echando al ruedo lo que tenéis, y perdéos, baila que baila, que bailando os ganaréis.
(Bailad los soles y las nieves lo que habéis y que no habéis;)/ $\backslash$ lo que tenéis y no I_tenéis. el día, al caer la noche / $\backslash$ ¿et día, al venir la noche la noche, al amanecer.

2 Bailad tas cosas que no bailan y a son y son las traeréis si los hermanos no acuden

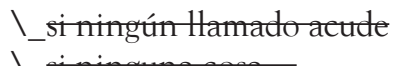
\_si ninguna cosa...

si los llamados no llegan todavía mejor bailéis.

3b Bailad los pastos floridos, con los que están por florecer

1_y los que están por florecer los trigos voleados recogidos ${ }^{33}$ los no sembrados también.

\section{Hoja 5}

3 Bailad los pastos floridos o que están por florecer: los trigos que ya segaron, los no sembrados también.

4 Romped la mancha de hierbas que las hierbas no rompéis la hierba amante retorne $\backslash$ Las hierbas vuelven $\backslash$ Eas hierbas amantes retornent y las bailáis otra vez

4 Bailad cuerpo y alma dando al ruedo lo que tenéis como piedras o luceros así desnudos bailéis.

33 Es probable que Mistral quisiera optar por uno de estos dos términos: "voleados", o "recogidos". El verso posee una variante que fue tachada: "Los trigos que ya segaron". 


\section{Hoja 7}

4 Bailad echando el daño/

\_Bailadetenerpo, bailadetalma

Bailad los años que tenéis/

$\backslash$ ¿eehad al ruedo lo que tenéis

y perdeos, baila y baila/

$\backslash$ _y perdeos, baila que baila que bailando no os perderéis/

\_que perdidos ganaréis y bailando no os perderéist

\_que bailando no perderéis

Bailad el día y la noche,

bailad y nunca paréis.

Los brazos dados al viento,

Bailad como que voléis.

Bailad como que soltárais vuestra vida de una vez y con un aire de eternos perdidamente bailéis.

Romped cebadas y trébol,

que ninguna hierba rompéis.

Hierbas rotas se levantan y las bailáis otra vez.
1 Bailad el día, y la noche; /

/_Bailad el día, bailady la noche bailad y nunca paréis.

Los brazos dados al viento, /

\_Brazos altos, al viento /

Brazos altosy al viento /

\_Eabello y brazos al viento ${ }^{34}$ bailad como que voléis.

\section{Hoja 8}

5 Bailad como que soltarais vuestra vida de una vez y con un aire de eternos, el aire eterno la danza eterna bailéis.

Perdidamente

\section{Hoja 9}

5 Romped cebadas y trébol/

\_Romped las hierbas, /

\_Romped alfalfasy [...] que ninguna hierba romperéis

\_rompéis

Las hierbas rotas se levanta(n) ${ }^{35}$ y las bailáis otra vez.

34 Este verso y el anterior se tachan con una equis.

35 Variantes del verso, tachadas: "El trébol roto se levanta", "La hierba rota se levanta". La poeta le agrega el plural al artículo, al sustantivo y al adjetivo, excepto al verbo. 


\section{Romped}

Bailad como que soltárais todo el mundo de una vez

Quebrad esta nuez del mundo este límite, esta sed..$^{36}$ y cuando os llamen los que duermen, Abrid el cielo con cantos /

$\backslash$ _Romped la tierra y [...]

mejor que nunca bailéis.

\section{Hoja 10}

Quebrad esta nuez del mundo, que rota la dejaréis.

Abrid el cielo cantando y en cielo abierto dancéis.

6 Quebrad esta nuez del mundo, que rota la dejaréis. ${ }^{37}$

Abrid el cielo cantando y en cielo abierto dancéis./

\_y en cielo abierto baitéis.

\section{Hoja 11}

Bailad como que soltarais todo el mundo de una vez /

\_vuestra vida de una vez y cuando ya perdáis todo /

\_y cuando ya

perdiereis todo /

$\backslash \_y$ cuando os llamen los

$\backslash$ _que duermen

mejor que nunca bailéis.

(que en la Ronda de [...]

bailáis sin corona

eon vosotros baila un Rey.

disfrazado

baila un Dios o baila el Rey

(y entrad a la ronda ${ }^{38}$

que de la ronda no saldréis.

36 Versión tachada: "esta muralla, esta sed". Se tachó "muralla" y se cambió el género del artículo demostrativo. En todo caso, el verso está marcado con una equis al lado izquierdo.

37 La versión que se consigna es la que finalmente convenció a la poeta, pues ensaya las siguientes variantes tachadas del verso: "estos metales, esta sed", "este metal con sed"; por último, escribe "esta ceguera, esta sed". Sin embargo, la poeta marca una equis al lado izquierdo del verso, y escribe abajo la versión consignada.

38 Solo con el primer paréntesis en el original. 
Es probable que el texto haya tenido otras versiones preliminares; en este manuscrito las hojas uno, cinco y ocho evidencian muestras de borrones, por lo que es notorio que el poema se reescribió numerosas veces.

En Almácigo, Luis Vargas Saavedra incluye como poema los dos fragmentos de este manuscrito escritos por el reverso, al que titula "La sabuesa Muerte" (2009, p. 215). En la columna de la izquierda aparece el texto que se editó, y en la columna derecha se transcriben las hojas pertinentes del manuscrito:

\section{La sabuesa Muerte \\ La que salta a las rodillas, la sabuesa Muerte, y roba al niño del regazo, caiga quebrada del rayo, caiga inmediatamente y como la res en pavesas. Se muera la Muerte.}

\section{Hoja 2}

la que salta a las rodillas

la sabuesa Muerte

al niñopropio

salta y roba

to saca del regazo

la sabuesa Muerte

El rayo

Caiga quebrada del rayo

noatine no

eomo árbot

Caiga inmensamente

Como la res en pavesas

heeha pavesas

engran humo y gran

se muera la Muerte

\section{Hoja 6}

Ande en vano, pene en vano y no se lo encuentre.

Ande en vano, pene en vano y no se lo encuentre y si lo encuentra, Dios mío; herida se quede.

Y si lo encuentra, Dios mío, herida se quede.

En una primera lectura, los versos de las hojas dos y seis se perciben descontextualizados de la ronda, pues en esta predomina la imagen de la danza, y en la otra el tema de la muerte temprana de un niño. Sin embargo, una lectura más acuciosa puede reconocer a la 
muerte como un escenario más de esta danza cósmica. En las hojas ocho y once la poeta escribe: "Bailad como que soltarais / vuestra vida de una vez". De esta manera, la danza durante la vida constituye la antesala de una danza mejor luego de la muerte, pues en la hoja once se enuncia: "y cuando os llamen los que duermen / mejor que nunca bailéis". Estos versos se suceden luego de la estrofa de la hoja diez: "Quebrad esta nuez del mundo, / que rota la dejaréis. /Abrid el cielo cantando / y en cielo abierto dancéis". Los versos citados nos permiten afirmar que esta imagen vital de la danza se configura entrelazada con la muerte desde las primeras versiones del poema, lo que Mistral fue depurando en las sucesivas versiones, de tal forma que de una especie de "danza macabra", el texto se depura hasta la forma de una ronda infantil en apariencia ingenua y dulce, pero que retiene veladamente la presencia de la muerte en la estrofa quinta del poema publicado en Lagar II: "Haced como que soltaseis / vuestra vida de una vez; / y con son y ritmo eternos / la danza eterna bailéis".

Gracias a las versiones preliminares del poema, podemos reconocer a "la danza eterna" como la muerte, cuya cara más feroz, la "sabuesa" roba niños, se ubica físicamente oculta tras la danza, en dos reversos del manuscrito; de este modo, podemos postular que este "Convite a la danza" es en realidad una invitación a esperar la muerte como un eslabón más de lo que significa vivir; esta particular danza es un vehemente deseo por ocultar el rostro más terrible de la muerte, es decir, el desgarro, la pérdida, el despojo y el dolor; asimismo, la alegría de la danza disfraza la rebeldía frente a la muerte, manifestada en el anhelo de que "se muera" "hecha pavesas", que se descartó en las versiones posteriores.

Por último, es tarea de los lectores de Mistral enjuiciar los criterios de edición, pues es discutible la condición de inéditos de los poemas "Convite" y "La sabuesa Muerte"; lo son en cuanto constituyen materiales que no habían sido publicados por la poeta, pero no son en realidad proyectos de escritura separados, sino que forman parte de una versión preliminar del poema "Convite a la danza", por lo que, desde mi punto de vista, es necesario leerlos y comentarlos de acuerdo con su contexto originall 


\section{Referencias}

Alone (s. f.). [Carta a Doris Dana, ca. 1957]. Biblioteca Nacional Digital de Chile (Archivo del Escritor / Gabriela Mistral N. AE0022326), Santiago de Chile [en línea]. Recuperado de https://bit.ly/2tiEMII

Arce, M. \& García Carrillo, E. (1989). Gabriela Mistral y Joaquín García Monge: una correspondencia inédita. Santiago de Chile: Andrés Bello.

Arce, M. \& Bussche, G. (1993). Proyecto preservación y difusión del legado literario de Gabriela Mistral. Santiago de Chile: Editora Zig-Zag.

Bellemin-Nöel, J (1972). Le texte et l'avant-texte. Les brouillons d'une poème de Milosz. París: Larousse.

Biasi, P.-M. (2008). ¿Qué es un borrador? El caso Flaubert: ensayo de tipología funcional de los documentos de génesis. En E. Pastor Platero (Ed.), Genética textual (pp. 113-151). Madrid: Arco Libros.

Biasi, P.-M. (2011). Génétique des textes. París: CNRS.

Blecua, A. (2012). Estudios de genética textual. Madrid: Gredos.

Bussche, G. (1979, mayo 22). [Carta a Doris Dana]. Biblioteca Nacional Digital de Chile (Archivo del Escritor / Gabriela Mistral N. AE0022417), Santiago de Chile [en línea]. Recuperado de https:// bit.ly/2ys2D86

Bussche, G. (1983). Reino: Gabriela Mistral (poesía dispersa e inédita en versos y prosa). Valparaíso: Ediciones Universitarias de Valparaíso.

Bussche, G. (1992). Introducción a una lectura poética de Lagar II. Revista Mapocho, 31, 35-47. Recuperado de https://bit.ly/2tgnN3x

Cuneo, A. M. (1989). "El tiempo" de Gabriela Mistral, un poema en proceso constructivo. Acta Literaria, 14, 45-57.

Cuneo, A. M. (1990). La poética mistraliana. En AA. VV., Gabriela Mistral. Nuevas visiones (pp. 51-65). Valdivia: Universidad Austral de Chile. (Publicación del Anejo 13 de la revista de Estudios Filológicos de 1989, Homenaje al centenario de su natalicio)

Cuneo, A. M. (1998). Para leer a Gabriela Mistral. Santiago de Chile: Cuarto Propio.

Dana, D. (1957, febrero 1). [Carta a Alone]. Biblioteca Nacional Digital de Chile (Archivo del Escritor / Gabriela Mistral N.․ AE0022310). Santiago de Chile [en línea]. Recuperado de https://bit.ly/2JOVcNO

Dana, D. (1957, mayo 12). [Carta a Alone]. Biblioteca Nacional Digital de Chile (Archivo del Escritor / Gabriela Mistral N. AE0022312). Santiago de Chile [en línea]. Recuperado de https://bit.ly/2JX1K8U 
Dana, D. (1957, septiembre 8). [Carta a Alone]. Biblioteca Nacional Digital de Chile (Archivo del Escritor / Gabriela Mistral N.․ AE0022320). Santiago de Chile [en línea]. Recuperado de https://bit.ly/2K0vxB6

Dana, D. (s. f.). [Notas a Lagar II]. Biblioteca Nacional Digital de Chile (Archivo del Escritor / Gabriela Mistral N..$^{\circ}$ AE0022107), Santiago de Chile [en línea]. Recuperado de https://bit.ly/2JO86M4

Delpiano, M. O. (1982, noviembre 21). Gabriela Mistral: "En Chile yo sería la Gaby”. El Mercurio, Suplemento Artes y Letras, p. E.

Figueroa, V. (1933). La divina Gabriela. Santiago de Chile: El Esfuerzo.

Garrido Donoso, L. (2012). "No hay como una contadora para hacer contar": Mujer poeta en Gabriela Mistral. Santiago de Chile: Cuarto Propio.

Graña, M. C. (2014). Una reescritura y su traducción: "Electra en la niebla" de Gabriela Mistral. Orillas, 3, 1-15. Recuperado de https:// bit.ly/2JVLPv5

Grésillon, A. (1994). Éléments de critique génétique. Lire les manuscrits modernes. París: Presses universitaires de France.

Lagar II. (1995, marzo 31). El Nortino, Chile, p. 10.

Lagar II. (1995, abril 16). La Mañana, Chile, p. 5.

Leighton, J. (1957, mayo 15). [Carta a Doris Dana]. Biblioteca Nacional Digital de Chile (Archivo del Escritor / Gabriela Mistral N. ${ }^{\circ}$ AE0022314), Santiago de Chile [en línea]. Recuperado de https:// bit.ly/2JQxxwB

Marchese, A. y Forradellas, J. (2000). Diccionario de retórica, crítica y terminología literaria. Barcelona: Ariel.

Mistral, G. (1941). [La cajita de Olinalá. En Cuaderno 31 (pp. 155-156)]. Biblioteca Nacional Digital de Chile (Archivo del Escritor / Gabriela Mistral N. AE0013059), Santiago de Chile [en línea]. Recuperado de https://bit.ly/2M1dEQ1

Mistral, G. (1946). Antología de Gabriela Mistral. París: Gallimard.

Mistral, G. (1967). Poema de Chile. Santiago de Chile: Pomaire.

Mistral, G. (1968). Poesías completas (E. de Cáceres, Intr.). Madrid: Aguilar.

Mistral, G. (1985). Poema de Chile (J. Quezada, Ed.). Santiago de Chile: Seix Barral.

Mistral, G. (1990). Textos inéditos. En AA. VV., Gabriela Mistral. Nuevas visiones (pp. 13-20). Valdivia: Universidad Austral de Chile. (Publicación del Anejo 13 de la revista de Estudios Filológicos de 1989, Homenaje al centenario de su natalicio) 
Mistral, G. (1991). Lagar II. Santiago de Chile: Dirección de Bibliotecas, Archivos y Museos DIBAM.

Mistral, G. (1992 [1991]). Lagar II. En Antología Mayor (Vol. 1). Santiago de Chile: Cochrane.

Mistral, G. (2009). Almácigo. Poemas inéditos de Gabriela Mistral (L. Vargas Saavedra, Comp.). Santiago: Ediciones Universidad Católica de Chile.

Mistral, G. (2011). Baila y sueña. Rondas y canciones de cuna inéditas de Gabriela Mistral (L. Vargas Saavedra, Ed.). Santiago: Ediciones Universidad Católica de Chile.

Mistral, G. (s. f.). [Convite, manuscrito, 3 hojas]. Biblioteca Nacional Digital de Chile (Archivo del Escritor / Gabriela Mistral N. AE0013779), Santiago de Chile [en línea]. Recuperado de https://bit.ly/2I2z8JF

Mistral, G. (s. f.). [Convite, manuscrito, 11 hojas]. Biblioteca Nacional Digital de Chile (Archivo del Escritor / Gabriela Mistral N. ${ }^{\circ}$ AE0018419), Santiago de Chile [en línea]. Recuperado de https://bit. ly/2t7IQWF

Mistral, G. (s. f.). [Convite, manuscrito, 3 hojas]. Biblioteca Nacional Digital de Chile (Archivo del Escritor / Gabriela Mistral N. ${ }^{\circ}$ AE0013780), Santiago de Chile [en línea]. Recuperado de https://bit.ly/2JZbvqp

Mistral, G. (s. f.). [Convite, manuscrito, 2 hojas]. Biblioteca Nacional Digital de Chile (Archivo del Escritor / Gabriela Mistral N. AE0013781), Santiago de Chile [en línea]. Recuperado de https://bit.ly/2M45aaF

Mistral, G. (s. f.). [Convite a la danza, manuscrito, 2 hojas]. Biblioteca Nacional Digital de Chile (Archivo del Escritor / Gabriela Mistral N. AE0013782), Santiago de Chile [en línea]. Recuperado de https:/l bit.ly/2pbUzBW

Mistral, G. (s. f.). [Convite a la danza, manuscrito, 2 hojas]. Biblioteca Nacional Digital de Chile (Archivo del Escritor / Gabriela Mistral N. AE0013783), Santiago de Chile [en línea]. Recuperado de https:// bit.ly/2KOTzvO

Mistral, G. (s. f.). [Cuaderno, versión de Lagar, 56 hojas (Prólogo de Alone)]. Biblioteca Nacional Digital de Chile (Archivo del Escritor / Gabriela Mistral N. ${ }^{\circ}$ AE0015394), Santiago de Chile [en línea]. Recuperado de https://bit.ly/2yoCDL2

Mistral, G. (s. f.). [Cuaderno, Archivador 9, 318 pp.]. Biblioteca Nacional Digital de Chile (Archivo del Escritor / Gabriela Mistral N. ${ }^{\circ}$ AE0015393), Santiago de Chile [en línea]. Recuperado de https:// bit.ly/2K3j $\mathrm{jwU}$ 
Mistral, G. (s. f.). [Índices y listados de Lagar I y II, 29 pp.]. Biblioteca Nacional Digital de Chile (Archivo del Escritor / Gabriela Mistral N. AE0022109), Santiago de Chile [en línea]. Recuperado de https:// bit.ly/2I1BcSi

Mistral, G. (s. f.). [La cajita de Olinalá, manuscrito, 2 hojas]. Biblioteca Nacional Digital de Chile (Archivo del Escritor / Gabriela Mistral N. AE0014732), Santiago de Chile [en línea]. Recuperado de https:// bit.ly/2yjubNe

Mistral, G. (s. f.). [La cajita de Olinalá, manuscrito, 4 hojas]. Biblioteca Nacional Digital de Chile (Archivo del Escritor / Gabriela Mistral N. AE0013736), Santiago de Chile [en línea]. Recuperado de https:// bit.ly/2ylSnOW

Mistral, G. (s. f.). [La cajita de Olinalá, manuscrito, 6 hojas]. Biblioteca Nacional Digital de Chile (Archivo del Escritor / Gabriela Mistral N. AE0013272), Santiago de Chile [en línea]. Recuperado de https:// bit.ly/2M37Q8u

Mistral, G. (s. f.). [La cajita de Olinalá, manuscrito, 4 hojas]. Biblioteca Nacional Digital de Chile (Archivo del Escritor / Gabriela Mistral N. AE0018413), Santiago de Chile [en línea]. Recuperado de https:/l bit.ly/2tad3Eo

Mistral, G. (s. f.). [La cajita de Olinalá. En Cuaderno 180 (pp. 69-77)]. Biblioteca Nacional Digital de Chile (Archivo del Escritor / Gabriela Mistral N. ${ }^{\circ}$ AE0015283), Santiago de Chile [en línea]. Recuperado de https://bit.ly/2M44LFl

Oelker, D. (2011). Gabriela Mistral: su lectura de Antígona. En E. Faúndez y D. Oelker, (Eds.), Guardo el signo y agradezco. Aproximaciones críticas a la obra de Gabriela Mistral (pp. 151-167). Concepción, Chile: Universidad de Concepción.

Pastor Platero, E. (2008). La crítica genética: avatares y posibilidades de una disciplina. En E. Pastor Platero (Ed.), Genética textual (pp. 9-32). Madrid: Arco Libros.

Quezada, J. (1992). Comentario de Lagar II. Reseña, (5)12, 34.

Revista Orfeo. (1967). Homenaje a Gabriela Mistral. Santiago: Biblioteca Nacional de Chile.

Robino, C. (1991, septiembre 23-29). Gabriela Mistral ante la tumba, Lagar II. Revista Hoy, 740, 42-44.

Rojo, G. (1997). Dirán que está en la gloria... (Mistral). México: F. C. E. 
Russ, N. (1957, mayo 22). [Carta a Doris Dana]. Biblioteca Nacional Digital de Chile (Archivo del Escritor / Gabriela Mistral N. AE0022315), Santiago de Chile [en línea]. Recuperado de https://bit.ly/2JKlgtg

Sandoval, S. (2012). La tragedia griega en la poesía de Gabriela Mistral: lecturas abiertas de "Antígona" y "Electra en la niebla". Cuadernos de Aleph, 4, 1-16. Recuperado de https://bit.ly/2M3ctPU

Scarpa, R. E. (1976). Una mujer nada de tonta. Santiago de Chile: Andrés Bello.

Solo trece poemas aprobados por la Mistral contiene su libro póstumo, Lagar II. (1991, octubre 17). Las Últimas Noticias, p. 27.

Vargas Saavedra, L. (1985). El otro suicida de Gabriela Mistral. Santiago: Ediciones Universidad Católica de Chile.

Vargas Saavedra, L. (1991, diciembre 29). Lagar II. El Mercurio, Suplemento, p. 6.

Vargas Saavedra, L. (1990). Lagar II, de Gabriela Mistral. En AA. VV., Gabriela Mistral. Nuevas visiones (pp. 113-121). Valdivia: Universidad Austral de Chile. (Publicación del Anejo 13 de la revista de Estudios Filológicos de 1989, Homenaje al centenario de su natalicio)

Vauthier, B. y Gamba, J. (2012). Crítica genética y edición de manuscritos hispánicos contemporáneos. Salamanca: Ediciones Universidad de Salamanca.

Zegers, P. P. (1991). Prólogo. En G. Mistral, Antología Mayor (Vol. 1). Santiago de Chile: Cochrane. 